\title{
STUDY OF PRACTICES OF USE OF NASOGASTRIC TUBE DECOMPRESSION IN GASTROINTESTINAL TRACT SURGERY
}

\author{
R. G. Naniwadekar', Bhushan Shinde ${ }^{2}$, Neville Tata ${ }^{3}$, Roshan Chiranjeev ${ }^{4}$, Parag Kamboj ${ }^{5}$
}

1 Professor, Department of General Surgery, Krishna Institute of Medical Sciences and Research Centre, Karad. ${ }^{2}$ Resident, Department of General Surgery, Krishna Institute of Medical Sciences and Research Centre, Karad. ${ }^{3}$ Resident, Department of General Surgery, Krishna Institute of Medical Sciences and Research Centre, Karad. ${ }^{4}$ Resident, Department of General Surgery, Krishna Institute of Medical Sciences and Research Centre, Karad. ${ }^{5}$ Resident, Department of General Surgery, Krishna Institute of Medical Sciences and Research Centre, Karad.

\section{ABSTRACT}

\section{BACKGROUND}

Since its inception by Levin in 1921 and popularisation by Wangensteen in 1933, nasogastric suction has become one of the routine procedures in postoperative abdominal surgery and yet there is little scientific justification. With the advent of fast track and day care surgery in this modern era, the search for postoperative care protocols which reduces costs, post-operative morbidity and shortens the duration of hospital stay continues to dominate surgical practice.

\section{MATERIALS AND METHODS}

The study design is an observational prospective one, conducted in the Department of Surgery of Krishna Hospital and Medical Sciences, Karad. Over a period of 18 months between August 2014 and May 2016, a total of 314 cases of both sexes admitted to surgical wards and underwent emergency or elective abdominal operations were collected. Inclusion criteria included all gastrointestinal tract surgeries. Exclusion criteria included patients who underwent oesophagectomy (These patients needs nasogastric tube as an absolute indication) and patients of gynaecological surgeries. Patients were allocated into two groups: Group I (Those with nasogastric tube) and Group II (Those without nasogastric tube) and in both groups patients were divided into elective and emergency cases.

\section{RESULTS}

The distribution of duration of hospital stay differs significantly across two study groups (P value $<0.001)$. Significantly higher proportion of cases from Group 1 had higher length of hospital stay compared to Group 2 cases (P value $<0.001$ ). The distribution of duration of hospital stay differs significantly across two study groups (P value $<0.001$ ). Significantly, higher proportion of cases from Group 1 had higher length of hospital stay compared to Group 2 cases (P value $<0.001$ ). The distribution of duration of postoperative return of bowel sound differs significantly across two study groups ( $\mathrm{P}$ value $<0.001)$. Significantly, higher proportion of cases from Group 1 had higher duration of postoperative return of bowel sound compared to Group 2 cases (P value $<0.001)$. The distribution of incidence of pulmonary complications did not differ significantly across two study groups (P value $>0.05$ ).

\section{CONCLUSION}

The study recommends that routine use of NGT in patients undergoing abdominal surgery is unnecessary and unjustified. It should only be used in specific cases as a therapeutic measure, especially in those who present with gross abdominal distension and excessive vomiting.

Postoperatively, nasogastric decompression should be continued in surgeries of upper gastrointestinal tract like intestinal perforation primary closure, resection and anastomosis of upper gastrointestinal tract, biliary tract surgeries where upper gastrointestinal tract has been used for anastomosis and adhesiolysis surgeries, where patient usually remains in postoperative ileus. In these cases, nasogastric tubes should be used as a therapeutic rather than a prophylactic tool.

\section{KEYWORDS}

Nasogastric Tube Decompression, Gastrointestinal Tract Surgeries.

HOW TO CITE THIS ARTICLE: Naniwadekar RG, Shinde B, Tata N, et al. Study of practices of use of nasogastric tube decompression in gastrointestinal tract surgery. J. Evolution Med. Dent. Sci. 2017;6(13):1047-1051, DOI: 10.14260/Jemds/2017/225

\section{BACKGROUND}

Since its inception by Levin in 1921 and popularisation by Wangensteen in 1933, nasogastric suction has become one of the routine procedures in postoperative abdominal surgery and yet there is little scientific justification. The rationale for using nasogastric tube after gastrointestinal tract surgeries

Financial or Other, Competing Interest: None.

Submission 31-12-2016, Peer Review 29-01-2017,

Acceptance 04-02-2017, Published 13-02-2017.

Corresponding Author:

Dr. Bhushan Shinde,

Krishna Hospital Campus, Karad.

E-mail: bds123456@gmail.com

DOI: $10.14260 /$ jemds $/ 2017 / 225$ are multiple. Purported benefits include preventing postoperative gastric distention and associated nausea, vomiting and aspiration as well as treating bloating of post-operative ileus. With the advent of fast track and day care surgery in this modern era the search for postoperative care protocols, which reduces costs, post-operative morbidity and shortens the duration of hospital stay continues to dominate surgical practice.

A Nasogastric Tube (NGT) is a hollow cylindrical tube of soft rubber or plastic, inserted through a nostril down the oesophagus into the stomach for instilling liquid foods or other substances or for withdrawing air or gastric contents. ${ }^{1}$ There are several types of nasogastric tubes. These include Ryle's 
(commonly used), Levin's, Einhorn's, Maurice-Lee, MillerAbbott and Cantor's tubes to mention a few.

The history of abdominal decompression dates back a long time. John Hunter (1728 - 1793) devised a stomach tube for the administration of stimulants to persons undergoing artificial respiration. More than 100 years later, Gross and Einhorn (1909) introduced the duodenal tube. ${ }^{2}$

Gastrostomy was first proposed by Egenberg (1839) a Norwegian, as a justifiable operation when dealing with an oesophageal carcinoma. In 1849 Sedillot attempted the first gastrostomy, but the patient did not survive. In 1876, Verneuil reported the first successful gastrostomy and attributed the result to careful suturing of the visceral to the parietal peritoneum with silver wire. Bisgard (1942) advocated jejunal intubation with the tube brought out as a gastrostomy.

Horsley (1939) suggested this manoeuvre for decompression following a Billroth I gastrectomy. ${ }^{2}$

Gastrostomy remained a method of gastrointestinal decompression until the introduction of the nasogastric tube by Levin in 1921 and its use has remained relatively unchallenged until recently. In 1926, Me Iver $^{3}$ demonstrated that postoperative abdominal distension is due to swallowed air and can be prevented by a nasogastric tube. In the 1930s many surgeons adopted suction via an indwelling nasogastric tube, which had been popularised by Wangensteen and Paine in the conservative management of intestinal obstruction, paralytic ileus and as part of routine postoperative care of patients after elective gastric and other abdominal operations. ${ }^{4}$ Thereafter, nasogastric tube decompression has remained in use almost routinely in all patients who undergo major abdominal surgery. Nasogastric decompression following abdominal surgery, as a prophylactic measure for prevention of nausea, vomiting and abdominal distension is standard in most centres and many believe that intestinal decompression via a nasogastric tube is mandatory following such surgery.5,6 The concept being that postoperative ileus, which develops after most abdominal operations causes distension of the stomach, small as well as large intestines and is related to an increased incidence of complications including wound infection and wound dehiscence. ${ }^{6}$ However, for several decades now there has been doubt regarding the justification for routine gastric decompression in the immediate postoperative period after abdominal operation. The reason for that is, when a tube is left in position after operation it is often there as a safety valve, to ease the surgeon's mind rather than for any actual good that it confers on the patient.7-8 Despite being used frequently, nasogastric tubes have many problems and complications, which include discomfort (often the patient is more distressed by the tube than by the painful incision), interference with ventilation of the lungs and coughing to clear secretions, dryness of the mouth and pharynx from mouth breathing, necrosis of the nares and oesophagitis from reflux around the tube which lies across the gastro-oesophageal junction breaking the barrier normally provided by the lower oesophageal sphincter. Other complications include vomiting around the tube, fluid depletion and electrolyte derangement, which results in loss of $\mathrm{H}^{+}, \mathrm{Cl}^{\prime}, \mathrm{K}^{+}$and $\mathrm{Na}^{+}$and has to be replaced by intravenous fluids. Nasal bleeding, sinusitis, otitis media, parotitis, laryngitis, necrosis of the pharynx, retropharyngeal abscesses and oesophageal stricture have all been reported as complications. ${ }^{9}$

\section{MATERIALS AND METHODS}

The study design is an observational prospective one, conducted in the Department of Surgery of Krishna Hospital and Medical Sciences, Karad. Over a period of 18 months between August 2014 and May 2016, a total of 314 cases of both sexes admitted to surgical wards and underwent emergency or elective abdominal operations were collected. Inclusion criteria included all gastrointestinal tract surgeries.

Exclusion criteria included patients who underwent oesophagectomy (These patients need nasogastric tube as an absolute indication) and patients of gynaecological surgeries. Patients were allocated into two groups: Group I (Those with nasogastric tube) and Group II (Those without nasogastric tube) and in both groups patients were divided into elective and emergency cases.

\section{RESULTS}

\begin{tabular}{|c|c|c|c|c|}
\hline & \multicolumn{2}{|c|}{ Group $1(n=200)$} & \multicolumn{2}{|c|}{ Group 2 (n = 114) } \\
\hline $\begin{array}{c}\text { Surgery } \\
\text { Type }\end{array}$ & $\begin{array}{l}\text { No. of } \\
\text { Cases }\end{array}$ & $\begin{array}{c}\% \text { of } \\
\text { Cases }\end{array}$ & $\begin{array}{l}\text { No. of } \\
\text { Cases }\end{array}$ & $\begin{array}{c}\text { \% of } \\
\text { Cases }\end{array}$ \\
\hline Elective & 59 & 29.5 & 102 & 89.5 \\
\hline Emergency & 141 & 70.5 & 12 & 10.5 \\
\hline Total & 200 & 100.0 & 114 & 100.0 \\
\hline
\end{tabular}

Table 1. The Distribution of Type of

Surgery between Two Study Groups $(n=314)$

Values are $\mathrm{n}(\%$ of cases). Chi-Square value $=104.537, \mathrm{P}$ value $=0.001^{* * *}$ (Highly Significant).

Of 200 cases with nasogastric decompression used (Group 1), 59 cases $(29.5 \%)$ had elective surgery and 141 cases (70.5\%) had emergency surgery.

Of 114 cases with no nasogastric decompression used (Group 2), 102 cases (89.5\%) had elective surgery and 12 cases $(10.5 \%)$ had emergency surgery.

The distribution of type of surgery differs significantly across two study groups ( $\mathrm{P}$ value $<0.00$ ).

\begin{tabular}{|c|c|c|c|c|}
\hline \multirow[b]{2}{*}{$\begin{array}{l}\text { Surgery } \\
\text { Group }\end{array}$} & \multicolumn{2}{|c|}{$\begin{array}{c}\text { Group } 1 \\
(n=200)\end{array}$} & \multicolumn{2}{|c|}{$\begin{array}{c}\text { Group } 2 \\
(n=114)\end{array}$} \\
\hline & $\begin{array}{l}\text { No. of } \\
\text { Cases }\end{array}$ & $\begin{array}{c}\% \text { of } \\
\text { Cases }\end{array}$ & $\begin{array}{l}\text { No. of } \\
\text { Cases }\end{array}$ & $\begin{array}{c}\% \text { of } \\
\text { Cases }\end{array}$ \\
\hline Open Appendicectomy & 17 & 8.5 & 46 & 40.4 \\
\hline LAP Appendicectomy & 8 & 4.0 & 47 & 41.2 \\
\hline Adhesiolysis & 15 & 7.5 & 0 & 0.0 \\
\hline $\begin{array}{l}\text { Small Bowel Perforation } \\
\text { Primary Closure }\end{array}$ & 41 & 20.5 & 0 & 0.0 \\
\hline Small Bowel Anastomosis & 26 & 13.0 & 0 & 0.0 \\
\hline Small Bowel Colostomies & 11 & 5.5 & 0 & 0.0 \\
\hline Intussusception Reduction & 7 & 3.5 & 0 & 0.0 \\
\hline $\begin{array}{l}\text { Other Intraabdominal } \\
\text { Surgeries }\end{array}$ & 16 & 8.0 & 6 & 5.3 \\
\hline Open Cholecystectomy & 4 & 2.0 & 6 & 5.3 \\
\hline Lap Cholecystectomy & 13 & 6.5 & 8 & 7.0 \\
\hline $\begin{array}{l}\text { Large Bowel RA Including } \\
\text { Colectomy }\end{array}$ & 17 & 8.5 & 0 & 0.0 \\
\hline Large Bowel Colostomies & 8 & 4.0 & 0 & 0.0 \\
\hline $\begin{array}{l}\text { Biliary Tract Surgeries (CBD } \\
\text { Exploration, Whipple) }\end{array}$ & 2 & 1.0 & 0 & 0. \\
\hline $\begin{array}{l}\text { Obstructed Hernia Surgery By } \\
\text { Adhesiolysis and Repair }\end{array}$ & 11 & 5.5 & 1 & 0.9 \\
\hline Colostomy Closure & 3 & 1.5 & 0 & 0.0 \\
\hline $\begin{array}{l}\text { LAP Appendicectomy with LAP } \\
\text { Cholecystectomy }\end{array}$ & 1 & 0.5 & 0 & 0.0 \\
\hline Total & 200 & 100.0 & 114 & 100.0 \\
\hline  & 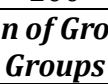 & $1-2=0$ & rger] & \\
\hline
\end{tabular}


Values are $\mathrm{n}$ ( $\%$ of cases). Chi-Square Value $=176.131$, Pvalue $=0.001^{* *}$ (Highly significant). In a group of 200 cases with nasogastric decompression used (Group 1), the commonest type of surgery was small bowel perforation primary closure.

In a group of 114 cases with no nasogastric decompression used (Group 2), the commonest type of surgery was LAP appendicectomy.

The distribution of type of surgery differs significantly across two study groups (P value $<0.001)$.

\begin{tabular}{|c|c|c|c|c|}
\hline & \multicolumn{2}{|c|}{$\begin{array}{c}\text { Group 1 } \\
(\mathbf{n = 2 0 0})\end{array}$} & \multicolumn{2}{c|}{$\begin{array}{c}\text { Group 2 } \\
\text { (n= 114) }\end{array}$} \\
\hline $\begin{array}{c}\text { Length of Hospital } \\
\text { Stay (Days) }\end{array}$ & $\begin{array}{c}\text { No. of } \\
\text { Cases }\end{array}$ & $\begin{array}{c}\text { \% of } \\
\text { Cases }\end{array}$ & $\begin{array}{c}\text { No. of } \\
\text { Cases }\end{array}$ & $\begin{array}{c}\text { \% of } \\
\text { Cases }\end{array}$ \\
\hline < 7 Days & 67 & 33.5 & 112 & 98.2 \\
\hline 8 - 14 Days & 118 & 59.0 & 1 & 0.9 \\
\hline > 14 Days & 15 & 7.5 & 1 & 0.9 \\
\hline Total & $\mathbf{2 0 0}$ & $\mathbf{1 0 0 . 0}$ & $\mathbf{1 1 4}$ & $\mathbf{1 0 0 . 0}$ \\
\hline \multicolumn{3}{|c|}{ Table 3. The Distribution of Length of Hospital } \\
Stay between Two Study Groups (n= 314) \\
\hline
\end{tabular}

Values are $\mathrm{n}(\%$ of cases). Chi-Square value $=124.372, \mathrm{P}$ value $=0.001^{* * *}$ (Highly significant).

Of 200 cases with nasogastric decompression used (Group 1), 67 cases $(33.5 \%)$ required less than 7 days hospital stay, 118 cases $(59.0 \%)$ had $8-14$ days of hospital stay and 15 cases $(7.5 \%)$ had more than 14 days of hospital stay.

Of 114 cases with no nasogastric decompression used (Group 2), 112 cases (98.2\%) required less than 7 days hospital stay, 1 case $(0.9 \%)$ had 8 - 14 days of hospital stay and 1 cases $(0.9 \%)$ had more than 14 days of hospital stay.

The distribution of duration of hospital stay differs significantly across two study groups ( $\mathrm{P}$ value $<0.001$ ) Significantly higher proportion of cases from Group 1 had higher length of hospital stay compared to Group 2 cases (P value $<0.001$ ).

\begin{tabular}{|c|c|c|c|c|}
\hline $\begin{array}{c}\text { Duration of } \\
\text { Post- } \\
\text { operative }\end{array}$ & \multicolumn{2}{|c|}{$\begin{array}{c}\text { Group 1 } \\
(\mathrm{n}=\mathbf{2 0 0}\end{array}$} & \multicolumn{2}{c|}{$\begin{array}{c}\text { Group 2 } \\
(\mathrm{n}=114)\end{array}$} \\
\hline $\begin{array}{c}\text { Return of } \\
\text { Bowel Sound }\end{array}$ & $\begin{array}{c}\text { No. of } \\
\text { Cases }\end{array}$ & $\begin{array}{c}\text { \% of } \\
\text { Cases }\end{array}$ & $\begin{array}{c}\text { No. of } \\
\text { Cases }\end{array}$ & $\begin{array}{c}\text { \% of } \\
\text { Cases }\end{array}$ \\
\hline NA & 11 & 5.5 & 0 & 0.0 \\
\hline $1-3$ days & 140 & 70.0 & 113 & 99.1 \\
\hline $4-6$ days & 49 & 24.5 & 1 & 0.9 \\
\hline Total & $\mathbf{2 0 0}$ & $\mathbf{1 0 0 . 0}$ & $\mathbf{1 1 4}$ & $\mathbf{1 0 0 . 0}$ \\
\hline $\begin{array}{c}\text { Table 4. The Distribution of Duration of Postoperative } \\
\text { Return of Bowel Sound between Two Study Groups } \\
\text { (n=314) }\end{array}$ \\
\hline
\end{tabular}

Values are $\mathrm{n}(\%$ of cases). Chi-Square value $=39.360, \mathrm{P}$ value $=0.001^{* * *}$ (Highly significant).

Of 200 cases with nasogastric decompression used (Group 1), 140 cases $(70.0 \%)$ had 1 - 3 days of duration of postoperative return of bowel sound, 49 cases (24.5\%) had 4 6 days' duration of postoperative return of bowel sound.

Of 114 cases with no nasogastric decompression used (Group 2), 113 cases (99.1\%) had 1 - 3 days of duration of postoperative return of bowel sound, 1 case $(0.9 \%)$ had $4-6$ days' duration of postoperative return of bowel sound.

The distribution of duration of postoperative return of bowel sound differs significantly across two study groups ( $P$ value $<0.001)$. Significantly higher proportion of cases from
Group 1 had higher duration of postoperative return of bowel sound compared to Group 2 cases (P value $<0.001$ ).

\begin{tabular}{|c|c|c|c|c|}
\hline $\begin{array}{c}\text { Duration of } \\
\text { Postoperative }\end{array}$ & \multicolumn{2}{|c|}{$\begin{array}{c}\text { Group 1 } \\
\text { (n=200) }\end{array}$} & \multicolumn{2}{c|}{$\begin{array}{c}\text { Group 2 } \\
\text { (n=114) }\end{array}$} \\
\hline Passage Flatus & $\begin{array}{c}\text { No. of } \\
\text { Cases }\end{array}$ & $\begin{array}{c}\text { \% of } \\
\text { Cases }\end{array}$ & $\begin{array}{c}\text { No. of } \\
\text { Cases }\end{array}$ & $\begin{array}{c}\text { \% of } \\
\text { Cases }\end{array}$ \\
\hline NA & 14 & 7.0 & 0 & 0.0 \\
\hline $1-3$ days & 77 & 38.5 & 113 & 99.1 \\
\hline 4 - 7 days & 109 & 54.5 & 1 & 0.9 \\
\hline Total & $\mathbf{2 0 0}$ & $\mathbf{1 0 0 . 0}$ & $\mathbf{1 1 4}$ & $\mathbf{1 0 0 . 0}$ \\
\hline
\end{tabular}

Table 5. The Distribution of Duration of Postoperative Passage of Flatus between Two Study Groups $(n=314)$

Values are $\mathrm{n}(\%$ of cases). Chi-Square value $=111.681, \mathrm{P}$ value $=0.001^{* * *}$ (Highly significant).

Of 200 cases with nasogastric decompression used (Group 1), 77 cases (38.5\%) had 1 - 3 days of duration of postoperative passage of flatus, 109 cases (54.5\%) had 4 - 7 days' duration of postoperative passage of flatus.

Of 114 cases with no nasogastric decompression used (Group 2), 113 cases (99.1\%) had 1 - 3 days of duration of postoperative passage of flatus, 1 case $(0.9 \%)$ had $4-7$ days' duration of postoperative pass flatus.

The distribution of duration of postoperative passage of flatus differs significantly across two study groups ( $\mathrm{P}$ value < 0.001). Significantly higher proportion of cases from Group 1 had higher duration of postoperative passage of flatus compared to Group 2 cases (P value < 0.001).

\begin{tabular}{|c|c|c|c|c|}
\hline $\begin{array}{c}\text { Vomiting/ } \\
\text { Reinsertion }\end{array}$ & \multicolumn{2}{|c|}{$\begin{array}{c}\text { Group 1 } \\
\text { (n= 200) }\end{array}$} & \multicolumn{2}{c|}{$\begin{array}{c}\text { Group 2 } \\
\text { (n= 114) }\end{array}$} \\
\hline & $\begin{array}{c}\text { No. of } \\
\text { Cases }\end{array}$ & $\begin{array}{c}\text { \% of } \\
\text { Cases }\end{array}$ & $\begin{array}{c}\text { No. of } \\
\text { Cases }\end{array}$ & $\begin{array}{c}\text { \% of } \\
\text { Cases }\end{array}$ \\
\hline No & 198 & 99.0 & 112 & 98.2 \\
\hline Yes & 2 & 1.0 & 2 & 1.8 \\
\hline Total & $\mathbf{2 0 0}$ & $\mathbf{1 0 0 . 0}$ & $\mathbf{1 1 4}$ & $\mathbf{1 0 0 . 0}$ \\
\hline \multicolumn{3}{|c|}{$\begin{array}{r}\text { Table 6. The Distribution of Postoperative } \\
\text { Incidence of Vomiting/Reinsertion } \\
\text { between Two Study Groups (n=314) }\end{array}$}
\end{tabular}

Values are $\mathrm{n}(\%$ of cases). Chi-Square value $=4.653, \mathrm{P}$ value $=0.325 \mathrm{NS}$ (Non-Significant).

Of 200 cases with nasogastric decompression used (Group 1), 2 cases $(1.0 \%)$ required reinsertion.

Of 114 cases with no nasogastric decompression used (Group 2), 2 cases (1.8\%) required reinsertion.

The distribution of incidence of vomiting/reinsertion did not differ significantly across two study groups (P value > 0.05).

\begin{tabular}{|c|c|c|c|c|}
\hline Pulmonary & \multicolumn{2}{|c|}{ Group $1(n=200)$} & \multicolumn{2}{|c|}{ Group $2(n=114)$} \\
\hline Complications & $\begin{array}{l}\text { No. of } \\
\text { Cases }\end{array}$ & $\begin{array}{c}\% \text { of } \\
\text { Cases }\end{array}$ & $\begin{array}{l}\text { No. of } \\
\text { Cases }\end{array}$ & $\begin{array}{c}\% \text { of } \\
\text { Cases }\end{array}$ \\
\hline No & 193 & 96.5 & 114 & 100.0 \\
\hline Yes & 7 & 3.5 & 0 & 0.0 \\
\hline Total & 200 & 100.0 & 114 & 100.0 \\
\hline $\begin{array}{r}\text { Table } 7 . \\
\text { Incider } \\
\text { betwe }\end{array}$ & $\begin{array}{l}\text { e Distr } \\
\text { of Pul } \\
\text { Two St }\end{array}$ & $\begin{array}{l}\text { tion of } \\
\text { nary Co } \\
\text { y Group }\end{array}$ & $\begin{array}{l}\text { stoperat } \\
\text { plication } \\
(n=314)\end{array}$ & \\
\hline
\end{tabular}

Values are $\mathrm{n}(\%$ of cases). Chi-Square value $=4.081$, $\mathrm{P}$ value $=0.043^{*}$ (Significant).

Of 200 cases with nasogastric decompression used (Group 1), 7 cases $(3.5 \%)$ had pulmonary complications. 
Of 114 cases with no nasogastric decompression used (Group 2), none had pulmonary complications.

The distribution of incidence of pulmonary complications did not differ significantly across two study groups ( $\mathrm{P}$ value > $0.05)$.

\begin{tabular}{|c|c|c|}
\hline $\begin{array}{c}\text { Grade of } \\
\text { Intolerance }\end{array}$ & $\begin{array}{l}\text { No. of } \\
\text { Cases }\end{array}$ & $\begin{array}{c}\% \text { of } \\
\text { Cases }\end{array}$ \\
\hline Grade 1 & 24 & 12.0 \\
\hline Grade 2 & 93 & 46.5 \\
\hline Grade 3 & 74 & 37.0 \\
\hline Grade 4 & 9 & 4.5 \\
\hline Total & 200 & 100.0 \\
\hline
\end{tabular}

Table 8. The Distribution of the Group 1 Cases according to the Grade of Intolerance to Tube $(n=200)$

Values are $\mathrm{n}(\%$ of cases).

Of 200 cases from Group 1, 24 cases (12.0\%) had Grade 1 intolerance, 93 cases (46.5\%) had Grade 2 intolerance, 74 cases $(37.0 \%)$ had Grade 3 intolerance and 9 cases $(4.5 \%)$ had Grade 4 intolerance to tube

\section{DISCUSSION}

Total 314 patients were studied in this study; patients were distributed in Group 1 and Group 2 as patient with nasogastric tube and without nasogastric tube respectively. Of 314 cases studied, nasogastric decompression was used in 200 cases $(63.7 \%)$ and in 114 cases $(36.3 \%)$ it was not used.

Out of $314,161(51.37 \%)$ were elective surgeries and 153 (48.72\%) are emergency. Of 200 cases with nasogastric decompression used (Group 1), 59 cases (29.5\%) had elective surgery and 141 cases $(70.5 \%)$ had emergency surgery.

However, Bauer JJ, Gelernt IM, Salhy BA, Kreel I, Essenhigh DM. Argov SA, Goldstein I, Brazilai A, Cheadle WD, Vitale GC, Mackie CR, Cuschieri A et al, studies showed equal distribution of cases in both groups.

Of 114 cases with no nasogastric decompression used (Group 2), 102 cases (89.5\%) had elective surgery and 12 cases $(10.5 \%)$ had emergency surgery.

In this study various types of surgeries are included, to compare those surgeries according to nasogastric tube significance they were categorised in different groups, surgeries categorised in single group have same nasogastric decompression significance with or without use of it.

In a group of 200 cases with nasogastric decompression used (Group 1), the commonest type of surgery was small bowel perforation closure 41 cases (20.5\%).

In a group of 114 cases with no nasogastric decompression used (Group 2), the commonest type of surgry was laparoscopic appendicectomy, 47 cases $(41.2 \%)$.

Total of 314 patients were studied (63.7\%) in Group I and $36.3 \%$ in Group II) and the findings showed that there were more patients in Group II (99.1\%) who had active bowel movement between day $1-3$ postoperatively compared to $70 \%$ in Group I. More patients had active bowel movement on day 4 - 6 postoperatively in Group I (24.5\%), but this is a larger percentage as compared to patients in Group II who had active bowel movement on day $4-6(0.9 \%)$ postoperatively. A total of 314 patients were studied (63.7\%) in Group I and 36.3\% in Group II) and the findings showed that there were more patients in Group II (99.1\%) who had passed flatus between day 1 - 3 postoperatively compared to 38.5\% in Group I. More patients had passed flatus on day $4-7$ postoperatively in Group I (54.5\%), but this is a larger percentage as compared to patients in Group II who had passed flatus on day 4 - 7 $(0.9 \%)$. \{There were 11 deaths $(5.5 \%$ cases $)$ in this study, which did not had bowel sounds or passed flatus\}.

Out of 189 patients (excluding 11 deaths) from Group 1, which had nasogastric decompression volume of aspirate was less than $300 \mathrm{~mL}$ on the previous day of removal of nasogastric tube. Above results can be explained by the presence of gastric secretion in the stomach, which can stimulate bowel activity by distending and stretching the muscle fibres of the stomach, hence initiating bowel movements. Such results are similar to those was reported by Cheadle et $\mathrm{al}^{6}$ and Pearl. Both studies found a significant number of patients in Group I who took a longer time to first passage of flatus, active bowel movement and discontinuation of intravenous fluids. However, there are other series, which have reported no significant difference in onset of bowel movements between the two groups. 8,10

This study therefore re-affirms the fact that the majority of patients without a nasogastric tube had early active bowel movement within the first two days postoperatively. Those who required nasogastric tube re-insertion had similar presentation (i.e. vomiting more than three times and gross abdominal distension) in both groups and their symptoms were relieved within twenty four hours of tube re-insertion, except one patient in Group I who had colostomy closure following sigmoidectomy due to sigmoid volvulus had to undergo re-laparotomy, because of a stenosis in the rectum possibly following previous surgery. This patient was initially operated as a case of colostomy closure following sigmoidectomy due to sigmoid volvulus and on the third day showed signs of active bowel movement and the nasogastric tube was removed, but twenty four hours later he presented with gross abdominal distension and vomiting after being allowed to start oral feeding.

In this study among the 314 cases 200 cases with nasogastric decompression used (Group 1), 67 cases (33.8\%) had RT duration of 1 - 3 days, 120 cases $(60.0 \%)$ had the RT duration of 4 - 7 days. This is similar to other studies. $3,4,5,6$

Out of 314 cases studied in this series amongst 200 cases $7(3.5 \%)$ cases of Group 1 with nasogastric tube had pulmonary complication in the form of pneumonia, which is confirmed on chest x-ray supported respiratory clinical findings. In a study reported by Dinsmore et al, 16 no. cases of pulmonary complication reported. One study reported equal distribution of pneumonia among the two groups, while other studies have reported higher number of patients with pneumonia in Group 1 with none in Group 2.3,5,6,10

Total 9 patients they were of Group 1 (with nasogastric tube 200 cases) had other complications, out of that 6 patients had anastomotic leak and 3 had ulcer over nose. Out of total 6 anastomotic leak, 3 patients had ileotransverse anastomosis leak on post-operative day 3 done in a case of traumatic intestinal perforations with significant contamination of peritoneal cavity, 3 patients had ileoileal anastomotic leak on post-operative day 4 operated for ileal perforations. There were no cases of anastomotic leak in Group 2, which are without nasogastric tube insertion. So whatever complications observed related to anastomotic leak in this study were in Group 1, which is with nasogastric tube and probable reason in anastomotic leak cases were contamination of abdominal cavity which is not related to nasogastric tube. The result 
corresponds to that reported by Ibrahim Efut is different in other studies. . $^{3-13}$

Several series presented no differences between two groups found in terms of wound infection.8,12 So wound dehiscence is not considered as parameter to compare between two groups in our study design. On the other hand Cheadle ${ }^{6}$ reported 6 patients in Group I and 4 patients in Group II, while Bauer et al $^{3}$ had 3 patients in Group I and 2 patients in Group II.

Discomfort was the single commonest problem in the majority of patients (55\%) with nasogastric tube. Discomfort was expressed by these patients differently, some felt difficulty in breathing or cough adequately and some felt throat and nasal irritation, so patient's discomfort has been recorded on scale of grade of intolerance. Out of 200 cases from Group 1, 24 cases $(12.0 \%)$ had Grade 1 intolerance (Discomfort only at ambulation), 93 cases (46.5\%) had Grade 2 intolerance (Patient requests to remove nasogastric tube), 74 cases (37.0\%) had Grade 3 intolerance (Patient tries to remove nasogastric tube) and 9 cases (4.5\%) had Grade 4 intolerance to tube (Patient removes nasogastric tube). That is suggestive of significant discomfort has been observed in Group 1 case with nasogastric tube.

Of 200 cases with nasogastric decompression used (Group 1), 67 cases $(33.5 \%)$ required less than 7 days hospital stay, 118 cases $(59.0 \%)$ had 8 - 14 days of hospital stay and 15 cases (7.5\%) had more than 14 days of hospital stay.

Of 114 cases with no nasogastric decompression used (Group 2), 112 cases (98.2\%) required less than 7 days hospital stay, 1 case $(0.9 \%)$ had 8 - 14 days of hospital stay and 1 case $(0.9 \%)$ had more than 14 days of hospital stay. Studies by Schwartz ${ }^{8}$ reported similar findings in term of hospital stay. The higher proportion of patient ready for discharge in Group II found between day 1 - 7 can be explained by the presence found intestinal contents that could stimulate bowel movements and contribute to early discontinuation of intravenous fluids, early start of ambulation and oral feeding, hence early discharge home and short hospital stay.

\section{CONCLUSION}

This study was conducted with the aim of determining the role of prophylactic nasogastric tube decompression in patients undergoing abdominal surgery. Three hundred and fourteen patients (200 patients with tube [Group I]) and 114 patients without tube [Group II] who presented for emergency or elective surgical intra-abdominal conditions at Krishna Hospital and Medical Research Centre, Karad, were studied.

The findings are that; the type of operations and age distribution of patients were different in the two groups.

Out of 114 patients in Group II, a total of 114 patients (95.8\%) were treated successfully without nasogastric tube decompression compared to 189 patients in Group I (i.e. after excluding eleven deaths). The rate of complications was generally higher in Group I than Group II patients. The commonest problem was discomfort reported in $62 \%$ of patients in Group I. Nasogastric tube re-insertion was necessary in both groups ( 2 patients in Group II and 2 patients in Group I). Deaths occurred in Group 1, but the causes of death in both groups were not related to the presence or absence of the NGT. The length of hospital stay and the onset of bowel movements were statistically significantly shorter among patients in Group II ( $\mathrm{p}<0.001)$.
The study recommends that routine use of NGT in patients undergoing abdominal surgery is unnecessary and unjustified. It should only be used in specific cases as a therapeutic measure, especially in those who present with gross abdominal distension and excessive vomiting.

Postoperatively, nasogastric decompression should be continued in surgeries of upper gastrointestinal tract like intestinal perforation primary closure, resection and anastomosis of upper gastrointestinal tract, biliary tract surgeries where upper gastrointestinal tract has been used for anastomosis and adhesiolysis surgeries where patient usually remains in postoperative ileus. In these cases, nasogastric tubes should be used as a therapeutic rather than a prophylactic tool.

Surgeries like appendicectomy either laparoscopic or open, cholecystectomy (laparoscopic or open) large bowel surgeries, other type of surgeries like biopsy of intraabdominal mass where bowel handling is minimal; in these surgeries use of nasogastric decompression can be avoided if use of it should be removed in 24 - 48 hours.

\section{REFERENCES}

[1] Miller BF, Keane. Encyclopedia and dictionary of medicine and nursing. WB Saunders Co 1972:p 986.

[2] Farris JM, Smith GK. An evaluation of temporary gastrostomy; a substitute for nasogastric suction. Ann Surg 1956;144(3):475-86.

[3] Bauer JJ, Gelernt IM, Salky BA, et al. Is routine postoperative nasogastric decompression really necessary? Ann Surg 1985;201(2):233-6.

[4] Essenhigh DM. Gastric decompression after abdominal Surgery. Br Med J 1973;1(5847):189-90.

[5] Argov S, Goldstein I, Brazilai A. Is routine use of the nasogastric tube justified in upper abdominal surgery? AMJ Surg 1980;139(6):849-50.

[6] Cheadle WG, Vitale GC, Mackie CR, et al. Prophylactic postoperative nasogastric decompression. A prospective study of its requirement and the influence of cimetidine in 200 patients. Ann Surg 1985;202(3):361-6.

[7] Kyle J. The management of gastroduodenal cases. In: Pye's surgical handcraft. 19th edn. John Wright and Sons Ltd 1969:348-50.

[8] Schwartz Cl, Heyman AS, Rao AC. Prophylactic nasogastric tube decompression: is its use justified? South Med J 1995;88(8):825-30.

[9] Schrock TR. Preoperative and postoperative care. In: handbook of surgery. $6^{\text {th }}$ edn. Jones Medical Publications 1978:35-6.

[10] Gerber A, Rogers FA, Smith LL. The treatment of paralytic ileus without the use of gastrointestinal suction. Surg Gynaecol obstet 1958;107(2):247-50.

[11] Ganong WF. Regulation of gastrointestinal function. In: review of medical physiology. $17^{\text {th }}$ edn. LANGE Medical book 1995:449,450,457,459,480.

[12] Pearl ML, Valea FA, Fischer M, et al. A randomized controlled trial of postoperative nasogastric tube decompression in gynaecologic oncology patients undergoing intra-abdominal surgery. Obstet Gynecol 1996;88(3):399-402.

[13] Beal JM, Preston FW. The digestive tract. In: basic surgical physiology. Year book publishers 1969:p 263. 